\title{
Research Paper: Normalization of the Non-word Repetition Test in Farsi-speaking Children
}

\author{
Hamidreza Farmani $^{1}$ (D), Fatemeh Sayyahi ${ }^{1}$ (D), Zahra Soleymani ${ }^{\text {* }}$ (D), Fariba Zadeh Labbaf ${ }^{1}$, Elnaz Talebi ${ }^{1}$, Zahra Shourvazi $^{1}$
}

1. Department of Speech Therapy, School of Rehabilitation, Tehran University of Medical Sciences, Tehran, Iran.

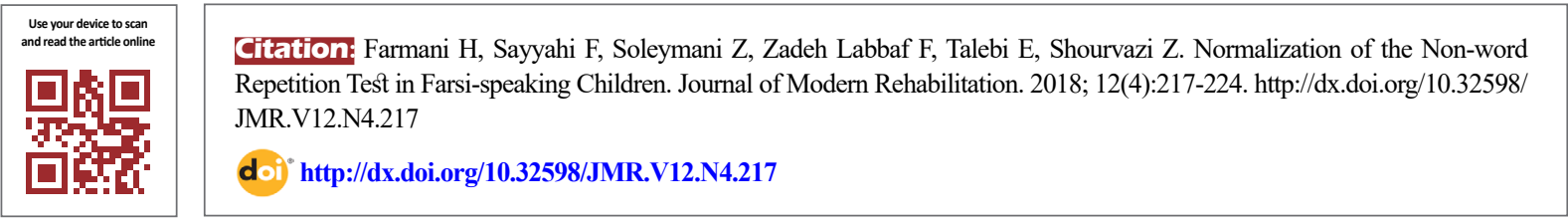

(c) (i) (5)

Article info:

Received: 13 May 2018

Accepted: 20 Aug 2018

Available Online: 01 Oct 2018

Keywords:

Non-word repetition,

Working memory, Normality,

Standardization test, Reliability

\begin{abstract}
Introduction: The Phonological Working Memory (PWM) plays an essential role in many cognitive functions, such as language acquisition. Impaired PWM can result in learning disability. Therefore, the existence of a standard test for the assessment of this ability, especially in children, is vital. Evidence suggests that the Non-Word Repetition (NWR) task is a good representative of PWM competence. This study aimed to normalize the NWR test for Farsispeaking children. Also, we aimed at assessing the external reliability of this test.
\end{abstract}

Materials and Methods: The NWR test, including main and parallel tests, was performed on 455 typically-developed children in five age groups ranging from four to nine years old. We attempted to have an almost equal number of participants in different socio-economic status groups and sexes.

Results: We found a remarkable relationship between the main and parallel test results $(\mathrm{P} \leq 0.001)$. There was a direct relationship between age and NWR performance in the main $(\mathrm{P} \leq 0.001)$ and the parallel $(\mathrm{P} \leq 0.001)$ tests. Also, boys obtained better total scores in the main $(\mathrm{P}=0.002)$ and the parallel $(\mathrm{P} \leq 0.001)$ tests.

Conclusion: The test has high external reliability. The results showed non-word repetition ability increased with age. The reported standard scores and normative data can be used for screening and assessing PWM among children.

\section{Introduction}

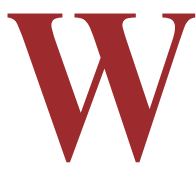

orking Memory (WM) is a kind of storage, responsible for temporarily saving environmental information and manipulate them [1]. Baddeley and Hitch presented a multi-component WM model, which became the basis of many further studies on WM [1]. This model included the phonological loop responsible for acoustic information processing, the visuospatial sketchpad for storing and manipulating visual and spatial environmental data, and the central executive component as the attentional control system [1]. They added the episodic buffer as the fourth component to the model, which acts as a linkage between WM and Long-Term Memory (LTM) for exchanging information

* Corresponding Author:

Zahra Soleymani, PhD.

Address: Department of Speech Therapy, School of Rehabilitation, Tehran University of Medical Sciences, Tehran, Iran.

Tel: +98 (912) 2036683

E-mail: soleymaniz@sina.tums.ac.ir 
Phonological loop involves two components: temporary storage and a subvocal rehearsal system. The subvocal rehearsal system helps to maintain the stored information with refreshing them. It also records visual information through the store, to provide ability of naming items [2]. The Phonological Working Memory (PWM) plays a significant role in complex human cognitive activities, such as control of action, mathematical learning, literacy, and linguistic processing [2-5]. A large amount of evidence shows the critical role of PWM in language acquisition [6-9]. Various tasks such as Non-Word Repetition (NWR), forward digit span, letter span, and word list recall are designed for assessing PWM [10-13].

The NWR task can be called as the most appropriate task for reflecting PWM competence [14]. In this task, the subject is being asked to repeat an unfamiliar phonetic sequence such as "bestial" immediately after hearing it [15]. Gathercole et al. for the first time provided and standardized a test to assess the PWM ability of English children. This test included 40 non-words. Later on, the same tests showed up in different languages [16-19]. Recently, the valid, reliable PWM tests in the Persian language were provided. These test had acceptable content validity. The tests had test-retest reliability $(\mathrm{r}=0.76$ and $\mathrm{ICC}=0.95, \mathrm{P} \leq 0.001)$ [20, 21]. There are similar valid and reliable NWR tests in the Persian language [22, 23]. A crucial psychometric aspect of every standardized test is to be normalized. For example, Gathercole et al. calculated the norm score by testing 612 children who were 4-9 years old [15]. By normalization of data, it is possible to compare the examinee's performance with the general population. So, researchers can interpret the subject's test scores with these data, while there are no reported normalization data for any NWR tests in the Persian language.

Considering the essential role of PWM in learning ability and the importance of the existence of a standardized test to evaluate this ability, we performed this study. This study aims to normalize the NWR test in 4-9-yearold children. To the best of our knowledge, it is the first study in normalizing an NWR test in the Persian language. Also, we aimed at comparing the scores between different ages and genders.

\section{Materials and Methods}

\section{Population and sampling methods}

This research was a cross-sectional and descriptive-analytic study. The initial number of participants was 455 children in 5 age groups between 4:00 and 8:11 (year: month). We selected the children from kindergartens and elementary school of Tehran City, Iran. We considered the impact of Socio-Economic Status (SES) in sampling. So, in each age group, we selected our participants almost equally through 4 different regions (north, south, east, and west) of Tehran. We considered children coming from the northern region as having high SES and children from the southern region as having low SES. The Eastern and western children were regarded as the middle SES group. Also, we tried to have male and female in equal number for each group. The inclusion criteria consisted of being monolingual, having normal language development, and lacking any psychiatric or hearing disorders. In the testing procedure, we planned to exclude the children, who were reluctant and inattentive to the tests. In this regard, 3 children did not complete the testing procedure.

\section{Research tools}

The valid and reliable NWR test in Persian was developed [20]. It consists of 25 non-words in 4 levels of length (1 syllable to 4 syllables). The parallel test with the same number of non-words also developed and the validity and reliability were assessed in older children [21]. The task was performed in a way that the child heard the pre-recorded non-word and asked to repeat it immediately as correct as possible. The non-words were recorded with a female voice, continual, and with 3 -seconds intervals. We recorded the participant's voices with a SONY ICD PX333 digital voice recorder for subsequent scoring. We scored 1 for correct answers and 0 for the wrong or ambiguous repetitions.

\section{Procedure}

The testing procedure was performed in the kindergartens and elementary schools in Tehran. We moved the children one by one to a quiet class and attempted to remove all distractive factors.

\section{Data analysis}

All the statistical analyses were performed in SPSS V. 24. To examine between-group differences, we recruited the Analysis of Variance (ANOVA) test and also Tukey HSD test, if necessary. We used the paired-samples $t$ test and independent samples t-test to compare the means scores of the two groups. The Pearson correlation coefficient was used to determine the relationship between the means of main and parallel test scores. The Pearson correlation was also used to examine the relationship 
between NWR scores and age groups. All the analyses were performed at the significance level of 0.05 .

\section{Results}

The data of 454 children ( 210 boys and 244 girls) in the main test and 453 children ( 208 boys and 245 girls) in the parallel test were gathered. Table 1 presents descriptive statistics. The mean score of the main test was significantly lower than the parallel test $(t=-11.57$, $\mathrm{P} \leq 0.001$ ). Also, we examined the relationship between the two tests scores. Data analysis showed a significant correlation between the scores of the main and parallel tests $(\mathrm{r}=0.52, \mathrm{P} \leq 0.001)$.

The ANOVA showed a remarkable difference between the different age groups in both tests. We found a direct relationship between the groups' age ranges and NWR mean scores (Figure 1). Tukey test revealed that the mean scores of the group No. 4 had a significant difference with groups No. $1(\mathrm{P}=0.005)$ and $2(\mathrm{P}=0.038)$; group No. 5 had a significant difference with groups No. $1(\mathrm{P} \leq 0.001), 2(\mathrm{P}=0.001)$, and $3(\mathrm{P}=0.002)$. In the parallel test, the mean scores of group No. 4 were significantly better than groups No. $1(\mathrm{P} \leq 0.004), 2(\mathrm{P}=0.002)$, and $3(\mathrm{P}=0.011)$. Also, the mean score of group No. 5 was significantly better than that of groups No. $1(\mathrm{P} \leq 0.001)$, $2(\mathrm{P} \leq 0.001)$, and $3(\mathrm{P}=0.001)$.
We assessed differences between genders with the independent samples $t$ test. We found that boys had a significantly better performance than girls in both tests (Table 2).

Also, we examined the children's performance among different SES groups. There were no differences between the mean scores of the main test $\left(\mathrm{F}_{3,450}=1.20\right.$, $\mathrm{P}=0.309$ ) among children coming from different regions of Tehran. While, in the parallel test, the analysis showed a significant between-group difference $\left(\mathrm{F}_{3}\right.$, ${ }_{449}=6.00, \mathrm{P}=0.001$ ). Tukey HSD showed that the group of children from the eastern regions got significantly lower scores than the children from the north $(\mathrm{P}=0.002)$ and south $(\mathrm{P}=0.001)$.

Table 3 presents the calculated Z-scores and standard scores of each age group for both tests. Also, the percentage of children in the minimum, maximum, and average score ranges are reported in Table 3. Figures 2 and 3 show the frequency distribution of participants' standard scores.

\section{Discussion}

The primary objective of this study was to normalize the NWR test among 4- to 9-year-old Farsi-speaking children. The provided standard scores for each age range could be used to compare the PWM ability of Far-

Table 1. Mean scores of the two tests in each group and between-group differences

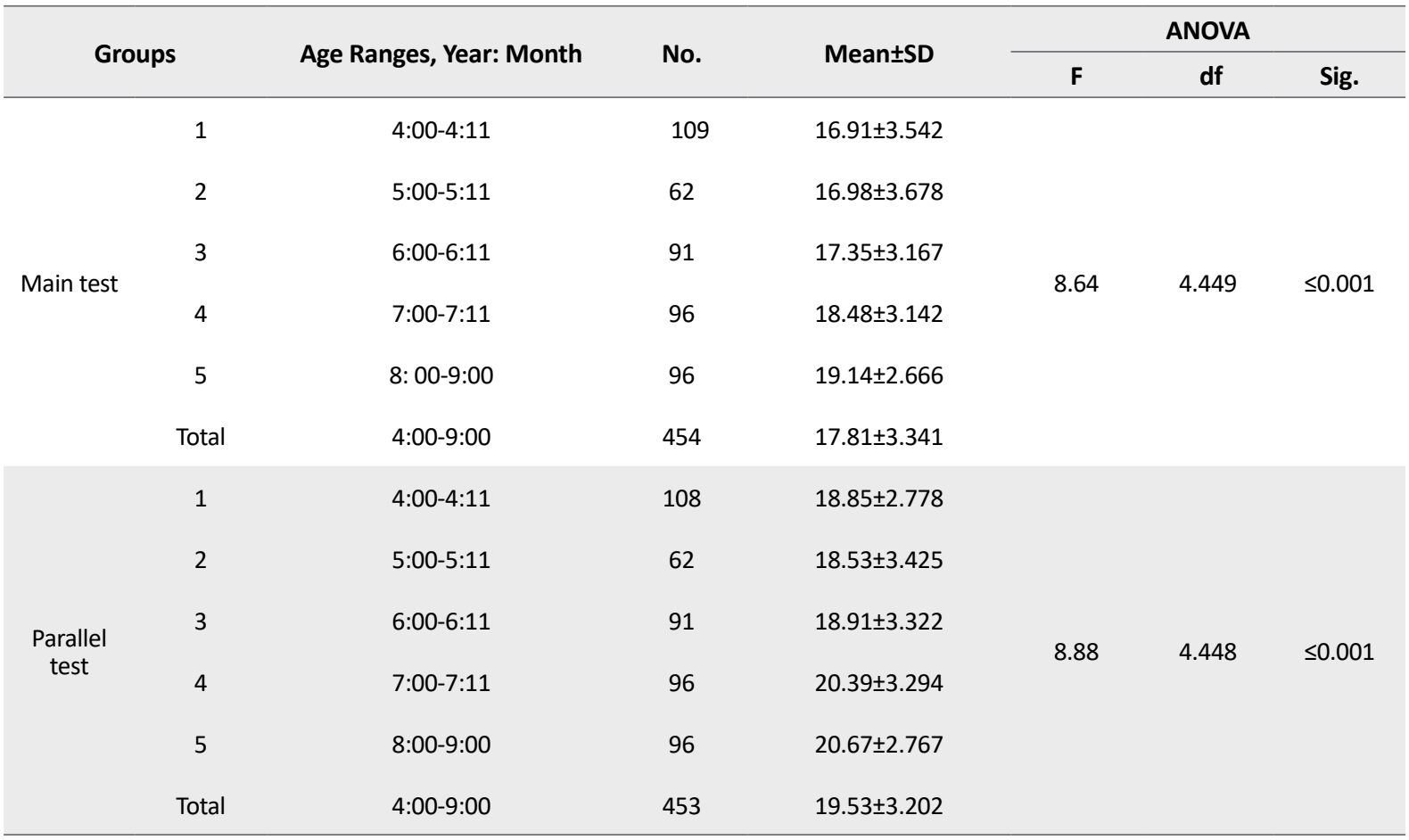

df: Degrees of freedom 


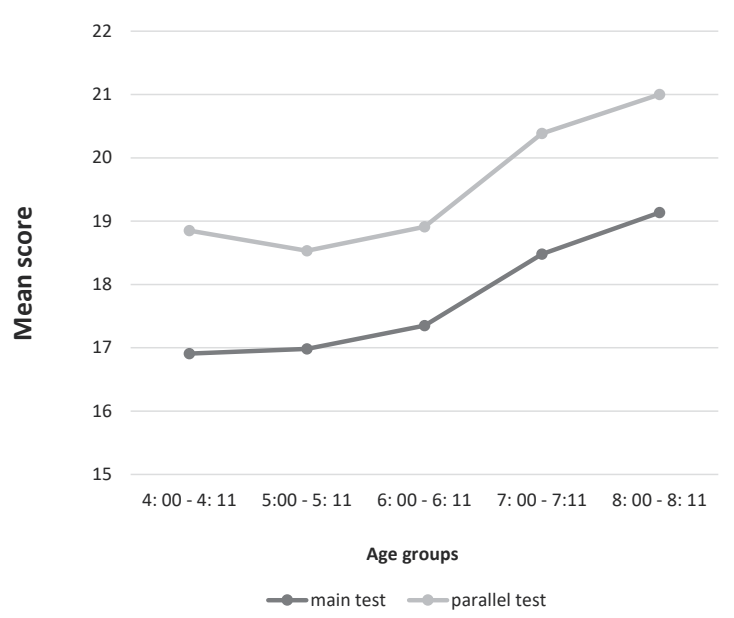

Figure 1. The relationship between the mean scores of NWR and age groups for the main and parallel tests

Table 2. Overall comparison between sexes for each test

\begin{tabular}{|c|c|c|c|c|c|}
\hline \multirow{2}{*}{ Tests } & \multirow{2}{*}{ Sex } & \multirow{2}{*}{ Mean \pm SD } & \multicolumn{3}{|c|}{ The Independent t-test } \\
\hline & & & $\mathbf{t}$ & df & Sig. \\
\hline \multirow{3}{*}{ Main test } & Male $(n=210)$ & $18.34 \pm 3.30$ & \multirow{3}{*}{10.11} & \multirow{3}{*}{1.45} & \multirow{3}{*}{0.002} \\
\hline & & & & & \\
\hline & Female $(n=244)$ & $17.35 \pm 3.31$ & & & \\
\hline \multirow{3}{*}{ Parallel test } & Male $(n=208)$ & $20.13 \pm 3.34$ & \multirow{3}{*}{14.12} & \multirow{3}{*}{1.45} & \multirow{3}{*}{$\leq 0.001$} \\
\hline & & & & & \\
\hline & Female $(n=245)$ & $19.02 \pm 2.98$ & & & \\
\hline
\end{tabular}

si-speaking children with the normal community. The results indicated that, in all age groups, few children obtained minimum $(\geq 69)$ or maximum $(\geq 131$ or $120-130)$ scores, and the majority of the children showed average performance (90-110). The raw scores of the examinees could be converted to the Z-scores to compare their ability to the mean score of that particular age range. The $\mathrm{Z}$-score is a numerical measurement, which shows that a data point is how many standard deviations below or above the mean score of that community [24].

We observed that the mean scores of the parallel test were significantly higher than those of the main test. In this regard, we should consider the point that in the testing procedure, both tests sets have been performed successively. Besides, the main test was completed before the parallel test for all participants. Although both NWR

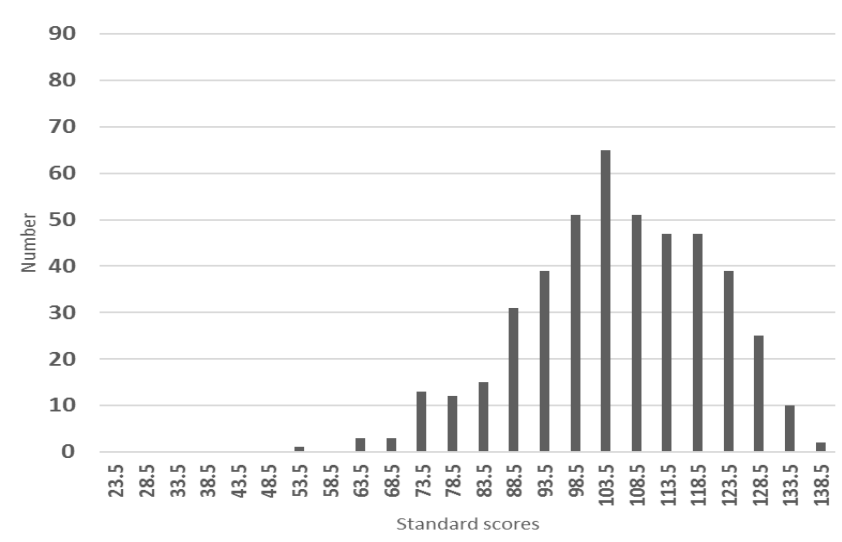

Figure 2. Distribution of the number of participants for standard scores in the main test 
Table 3. Z-scores and standard scores in each group

\begin{tabular}{|c|c|c|c|c|c|}
\hline Group & Age Range (Year:Month) & Tests & Standard Scores* & Percent of Participants & Z-score** \\
\hline 1 & $4: 00-4: 11$ & $\begin{array}{c}\text { Main test } \\
\text { Parallel test }\end{array}$ & $\begin{array}{c}\leq 69 \\
90-110 \\
\geq 131 \\
\leq 69 \\
90-110 \\
\geq 131\end{array}$ & $\begin{array}{c}2.8 \\
46.8 \\
0.9 \\
0.9 \\
58.3 \\
0.9\end{array}$ & -0.27 \\
\hline 2 & $5: 00-5: 11$ & $\begin{array}{c}\text { Main test } \\
\text { Parallel test }\end{array}$ & $\begin{array}{c}\leq 69 \\
90-110 \\
120-130 \\
\leq 69 \\
90-110 \\
120-130\end{array}$ & $\begin{array}{c}8.1 \\
51.6 \\
6.5 \\
4.8 \\
48.4 \\
4.8\end{array}$ & -0.24 \\
\hline 3 & $6: 00-6: 11$ & Parallel test & $\begin{array}{c}\leq 69 \\
90-110 \\
120-130 \\
\leq 69 \\
90-110 \\
120-130\end{array}$ & $\begin{array}{c}1.1 \\
48.4 \\
8.8 \\
5.5 \\
57.1 \\
3.3\end{array}$ & -0.13 \\
\hline 4 & 7:00-7:11 & Main test & $\begin{array}{c}\leq 69 \\
90-110 \\
120-130 \\
\leq 69 \\
90-110 \\
120-130\end{array}$ & $\begin{array}{c}1.0 \\
39.6 \\
10.4 \\
2.1 \\
64.6 \\
6.3\end{array}$ & 0.20 \\
\hline 5 & 8:00-8:11 & $\begin{array}{l}\text { Main test } \\
\text { Parallel test }\end{array}$ & $\begin{array}{c}\leq 69 \\
90-110 \\
\geq 131 \\
\leq 69 \\
90-110 \\
120-130\end{array}$ & $\begin{array}{c}1.0 \\
39.6 \\
2.1 \\
3.1 \\
58.3 \\
6.3\end{array}$ & 0.35 \\
\hline
\end{tabular}

*Standard score $=([$ Z-score $\times 15]+100) ;$ **Z-score $=($ raw score-Mean $) /$ standard deviation

tests sets were completely different, the findings suggest that children's performance will improve with becoming more familiar to the NWR task. However, the results revealed a remarkable correlation between the two test scores. This finding suggests the high external reliability of the NWR test and, indeed, both tests can be recruited to assess PWM ability without exception.

The findings of this study revealed that PWM performance had a direct relationship with chronological age. The NWR test involves many processes such as auditory processing, phonological processing, motor planning, and motor execution [25]. Therefore, obtaining more cognitive competence among typically-developing children by getting older is a good reason to receive better NWR scores. This finding agrees with previous studies in this regard [19, 26, 27]. Furthermore, the effect of more educational experiences is another reason. As all of our participants were selected from education centers; they were exposed to various daily educational experiences. As reported in the results, we saw a significant increase in the mean scores of 7-year-old children, who are almost concurrent with the elementary first grade. Also, we should notice an essential component of the 


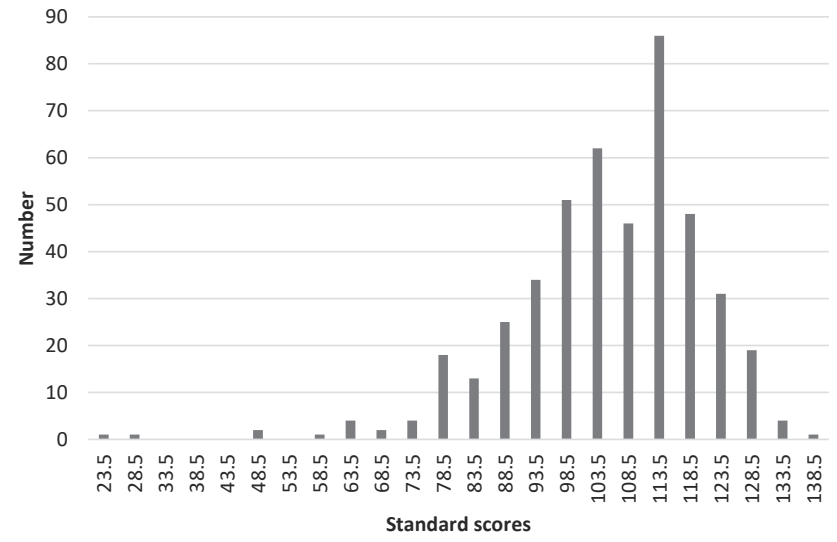

Figure 3. Distribution of the number of participants for standard scores in the parallel test

phonological loop in the subvocal rehearsal system. This component plays a critical role in PWM tasks. The subvocal rehearsal involvement increases with higher PWM demands like repeating non-words with more syllables. Evidence shows that the development of subvocal rehearsal component is after the sixth year [28]. Therefore, the slight differences in the age range before obtaining this ability and remarkable increasing after the sixth year is justifiable.

We observed an exception in the above paradigm. There was a slight reduction in the mean scores of the parallel test from the 4:00-4:11 to 5:00-5:11 age range. However, this reduction was not remarkable $(\mathrm{P}=0.967)$, and the mean difference was less than 0.25 . This phenomenon was also observed in a similar study in the United Kingdom [14].

To obtain a better normative data, an almost equal number of girls and boys were included in each age group. A general comparison of the girls and boys scores showed a better overall performance of boys in both test sets, while the results gathered from similar studies in other languages show an equal performance between sexes [19, 27]. Besides, as the normative data should represent the performance of the entire community with different SES, the probable impact of these factors on PWM was considered and NWR test was performed in 4 different regions of Tehran. We observed that children of the eastern areas of Tehran obtained lower scores than the northern and the southern regions of the parallel test. These different performances among different geographical areas have been already reported in similar studies $[19,27]$. Available evidence suggests that SES has an essential role in children's phonological development [29, 30]. However, as there was no difference between the southern, northern, and western groups as the represen- tative of low, high, and middle SES, the results did not implicate this conclusion in PWM ability. Furthermore, no difference was seen in the mean scores of the main test among different regions. The independence of phonological ability from SES was already reported in the study of Dodd et al. [31].

Because of the research and sampling conditions of the educational centers, as well as the high sample size, this research had some limitations. For example, the main and peer tests were not executed on different days. As another limitation, the number of participants of two sexes in our sample was not exactly equal in spite of our effort.

\section{Conclusions}

The NWR test has good external reliability. We found that NWR performance increases in children as a cause of education in addition to getting older. The normative data and standardize scores in the current study can be used to evaluate PWM ability in Farsi-speaking children.

\section{Ethical Considerations}

Compliance with ethical guidelines

This study was approved by the Ethics Committee of Tehran University of Medical Sciences (Code: 971.260). Before any testing, the written informed consent was received from the children's parents.

Funding

This research did not receive any specific grant from funding agencies in the public, commercial, or not-forprofit sectors. 


\section{Authors contributions}

Conceptualization: Zahra Soleymani, Fatemeh Sayyahi; Methodology: Zahra Soleymani, Fariba Zadeh Labbaf, Fatemeh Sayyahi; Investigation: all authors; Writing-original draft: Hamidreza Farmani, Fatemeh Sayyahi; Writing-review \& editing: Zahra Soleymani, Fariba Zadeh Labbaf, Fatemeh Sayyahi.

\section{Conflict of interest}

The authors declared no conflict of interest.

\section{Acknowledgements}

We are grateful to all teachers and students, who cooperated with us in the sampling procedure.

\section{References}

[1] Baddeley AD, Hitch G. Working memory. Psychology of Learning and Motivation. 1974; 8:47-89. [DOI:10.1016/S00797421(08)60452-1]

[2] Baddeley A. Working memory and language: An overview. Journal of Communication Disorders. 2003; 36(3):189-208. [DOI:10.1016/S0021-9924(03)00019-4]

[3] Bull R, Scerif G. Executive functioning as a predictor of children's mathematics ability: Inhibition, switching, and working memory. Developmental Neuropsychology. 2001; 19(3):273-93. [DOI:10.1207/S15326942DN1903_3] [PMID]

[4] Wagner RK, Torgesen JK, Rashotte CA, Hecht SA, Barker TA, Burgess SR, et al. Changing relations between phonological processing abilities and word-level reading as children develop from beginning to skilled readers: A 5-year longitudinal study. Developmental Psychology. 1997; 33(3):468-79. [DOI:10.1037/0012-1649.33.3.468] [PMID]

[5] Baddeley A, Chincotta D, Adlam A. Working memory and the control of action: Evidence from task switching. Journal of Experimental Psychology: General. 2001; 130(4):641-57. [DOI:10.1037/0096-3445.130.4.641] [PMID]

[6] Gathercole SE, Baddeley AD. Phonological memory deficits in language disordered children: Is there a causal connection? Journal of Memory and Language. 1990; 29(3):336-60. [DOI:10.1016/0749-596X(90)90004-J]

[7] Gathercole SE, Willis C, Baddeley AD. Differentiating phonological memory and awareness of rhyme: Reading and vocabulary development in children. British Journal of Psychology. 1991; 82(3):387-406. [DOI:10.1111/j.2044-8295.1991. tb02407.x]

[8] Gathercole SE, Baddeley AD. The role of phonological memory in vocabulary acquisition: A study of young children learning new names. British Journal of Psychology. 1990; 81(4):439-54. [DOI:10.1111/j.2044-8295.1990.tb02371.x]
[9] Michas IC, Henry LA. The link between phonological memory and vocabulary acquisition. British Journal of Developmental Psychology. 1994; 12(2):147-63. [DOI:10.1111/j.2044835X.1994.tb00625.x]

[10] Mehta MA, McGowan SW, Lawrence AD, Aitken MR, Montgomery AJ, Grasby PM. Systemic sulpiride modulates striatal blood flow: Relationships to spatial working memory and planning. Neuroimage. 2003; 20(4):1982-94. [DOI:10.1016/j.neuroimage.2003.08.007] [PMID]

[11] Kane MJ, Hambrick DZ, Tuholski SW, Wilhelm O, Payne TW, Engle RW. The generality of working memory capacity: A latent-variable approach to verbal and visuospatial memory span and reasoning. Journal of Experimental Psychology: General. 2004; 133(2):189-217. [DOI:10.1037/00963445.133.2.189] [PMID]

[12] Plaza M, Cohen H. The interaction between phonological processing, syntactic awareness, and naming speed in the reading and spelling performance of first-grade children. Brain and Cognition. 2003; 53(2):287-92. [DOI:10.1016/S02782626(03)00128-3]

[13] Lum JA, Conti-Ramsden G, Page D, Ullman MT. Working, declarative and procedural memory in specific language impairment. Cortex. 2012; 48(9):1138-54. [DOI:10.1016/j.cortex.2011.06.001] [PMID] [PMCID]

[14] Gardner H, Froud K, McClelland A, van der Lely HK. Development of the Grammar and Phonology Screening (GAPS) test to assess key markers of specific language and literacy difficulties in young children. International Journal of Language \& Communication Disorders. 2006; 41(5):513-40. [DOI:10.1080/13682820500442644] [PMID]

[15] Gathercole SE, Willis CS, Baddeley AD, Emslie H. The children's test of nonword repetition: A test of phonological working memory. Memory. 1994; 2(2):103-27. [DOI:10.1080/09658219408258940] [PMID]

[16] Santos FHd, Bueno OFA, Gathercole S. Errors in nonword repetition: Bridging short-and long-term memory. Brazilian Journal of Medical and Biological Research. 2006; 39(3):37185. [DOI:10.1590/S0100-879X2006000300008] [PMID]

[17] Radeborg K, Barthelom E, SjÖBerg M, Sahlén B. A Swedish non-word repetition test for preschool children. Scandinavian Journal of Psychology. 2006; 47(3):187-92. [DOI:10.1111/ j.1467-9450.2006.00506.x] [PMID]

[18] Roy P, Chiat S. A prosodically controlled word and nonword repetition task for 2-to 4-year-olds: Evidence from typically developing children. Journal of Speech, Language, and Hearing Research. 2004; 47(1):223-34. [DOI:10.1044/10924388(2004/019)]

[19] Chiat S, Roy P. The Preschool Repetition test: An evaluation of performance in typically developing and clinically referred children. Journal of Speech, Language, and Hearing Research. 2007; 50(2):429-43. [DOI:10.1044/1092-4388(2007/030)]

[20] Sayyahi F, Soleymani Z, Mahmoudi Bakhtiyari B, Jalaie S, [Providing a non word repetition test in 4-year-old Persian children and determining its validity and reliability (Persian)]. Audiology. 2011; 20(2):47-52.

[21] Soleymani Z, Amidfar M, Dadgar H, Jalaie S. Working memory in Farsi-speaking children with normal development and cochlear implant. International Journal of Pediat- 
ric Otorhinolaryngology. 2014; 78(4):674-8. [DOI:10.1016/j. ijporl.2014.01.035] [PMID]

[22] Afshar MR, Ghorbani A, Jalilevand N, Kamali M. [Providing the non-word repetition test and determining its validity and reliability and comparing phonological working memory in 4 to 6 Farsi-speaking normal and SSD children in Tehran City (Persian)]. Journal of Research in Rehabilitation Sciences. 2014; 9(5):899-911.

[23] Moossavi A, Khavarghazalani B, Lotfi Y, Mehrkian S, Bakhshi E, Mahmoodi Bakhtiari B. Validity and reliability of a non-sense syllable test for evaluating phonological working memory in Persian speaking children. Bimonthly AudiologyTehran University of Medical Sciences. 2014; 23(4):31-9.

[24] Lomax RG. An introduction to statistical concepts for education and behavioral sciences. London: Psychology Press; 2001. [DOI:10.4324/9781410605672]

[25] Gathercole SE. Complexities and constraints in nonword repetition and word learning. Applied Psycholinguistics. 2006; 27(4):599-613. [DOI:10.1017/S0142716406060383]

[26] Ebert KD, Kalanek J, Cordero KN, Kohnert K. Spanish nonword repetition: Stimuli development and preliminary results. Communication Disorders Quarterly. 2008; 29(2):6774. [DOI:10.1177/1525740108314861]

[27] Santos F, Bueno OFA. Validation of the Brazilian children's test of pseudoword repetition in Portuguese speakers aged 4 to 10 years. Brazilian Journal of Medical and Biological Research. 2003; 36(11):1533-47. [DOI:10.1590/ S0100-879X2003001100012] [PMID]

[28] Jarrold C, Baddeley AD, Hewes AK. Verbal short-term memory deficits in Down syndrome: A consequence of problems in rehearsal? Journal of Child Psychology and Psychiatry. 2000; 41(2):233-44. [DOI:10.1111/1469-7610.00604] [PMID]

[29] Templin MC. Certain language skills in children; their development and interrelationships. Minneapolis: University of Minnesota Press; 1957. [DOI:10.5749/j.ctttv2st]

[30] Burt L, Holm A, Dodd B. Phonological awareness skills of 4-year-old British children: An assessment and developmental data. International Journal of Language \& Communication Disorders. 1999;34(3):311-35. [DOI:10.1080/136828299247432]

[31] Dodd B, Holm A, Hua Z, Crosbie S. Phonological development: A normative study of British English-speaking children. Clinical Linguistics \& Phonetics. 2003; 17(8):617-43. [DO I:10.1080/0269920031000111348] 